\title{
Estructura administrativa y técnica para un modelo de gestión e investigación: La Alhambra
}

\author{
Mateo Revilla Uceda* \\ Jesús Bermúdez López***
}

La Alhambra ha carecido históricamente de dos instrumentos básicos para considerar la actividad arqueológica autónoma de otras actividades y poder planificar así actuaciones de mayor envergadura en el campo de la Conservación del Patrimonio: de un lado, una estructura administrativa y de gestión, y de otro una capacidad operativa de carácter técnico.

Con la vista puesta en la actualidad es evidente que la ausencia de una carta arqueológica del monumento y una revisión a fondo en un doble plano, esto es, el de los documentos de los archivos gráficos y escritos y el de las propias intervenciones de campo, se convierten en el objetivo prioritario para una correcta gestión patrimonial del monumento.

En este sentido, desde la aprobación de los Estatutos del Patronato de la Alhambra y Generalife en 1986 se ha venido trabajando en la dotación de unos servicios técnicos competentes con una mínima y lógica capacidad operativa, así como en la planificación y elaboración de una serie de programas de colaboración con numerosas instituciones e investigadores.

Vamos a comentar aquí simplemente las dos vertientes que ese tipo de actividad conlleva -siempre partiendo de la perspectiva arqueológica- en la Alhambra: por un lado el concepto de investigación, y por otro el concepto de difusión. Con respecto a la investigación es bastante significativo el objetivo de los Estatutos del Patronato de la Alhambra que no vamos a enumerar, lógicamente, pero sí a comentar la importancia que desde el punto de vista de la gestión patrimonial tienen como modelo. Tienen ya

* Director del Patronato de la Alhambra y Generalife

**Patronato de la Alhambra y Generalife la suficiente experiencia aplicada como para poder ser debatidos de una forma amplia y pensamos que este es el foro adecuado para ello. Entre los fines y funciones del Patronato de la Alhambra, figura en el apartado "c" "elaborar y desarrollar los planes de conservación, consolidación, mantenimiento, restauración, excavaciones e investigaciones de los bienes que están en el recinto monumental, velar para que dichos planes se atengan a los criterios más actualizados en materia de conservación y restauración de monumentos, y se desarrollen de acuerdo con los criterios propugnados en las cartas documentales internacionales elaboradas al respecto, así como para que se conserven las condiciones ambientales y paisaísticas del recinto monumental y su zona de protección". También corresponden al Patronato de la Alhambra "adoptar cuantas medidas cautelares sean necesarias para la conservación material, paisajistica y ambiental del recinto, así como para impedir sus usos contrastantes con su carácter histórico y con la fragilidad de sus condiciones materiales".

El apartado "h" asigna al Patronato de la Alhambra "el desarrollo de programas de investigación culturales, arqueológicos, epigráficos... etc., y de cooperación con otras instituciones culturales o centros de investigación afines".

El segundo instrumento, también de investigación, que nos gustaría resaltar y que no por conocido y criticado deja de ser menos útil, es el Plan Especial Alhambra-Alijares, iniciado en 1986 y que, entre otros, obtuvo el Premio Nacional de Urbanismo en 1987. Lo fundamental es que se trataba del primer Plan urbanístico que se elaboraba en España como consecuencia de la aprobación de la nueva Ley de Patrimonio Histórico en sustitución 
de la famosa Ley del 33. Aunque ya se había ejecutado uno en el momento de interregno entre ambas leyes, el de Santiago de Compostela, el de la Alhambra es el primero como Monumento. El Plan elaboró un documento muy sistemático, inédito hasta el momento, cuya característica fundamental es la asimilación de un principio pluridisciplinar cuando uno al enfrentarse a un documento histórico. En este Plan Especial son nueve los puntos programáticos que se dedican a la conservación del Patrimonio exclusivamente, insistimos, aplicados a la Alhambra, de los que extractamos los cinco primeros: establecimiento de un Programa de investigación arqueológica; segundo, un Programa de restauración; tercero, un Programa de estudio del estado físico de los elementos arquitectónicos; cuarto, la catalogación de protección monumental; quinto, la catalogación de espacios verdes. Vemos cómo la arqueología fue considerada con especial cuidado en el Plan.

Un tercer instrumento, que no podríamos definir como de carácter legal pero sí operativo, fue sin duda la ejecución del Proyecto para Infraestructuras del Monumento, entre 1987 y 1989. La Alhambra tenía que enfrentarse, como Conjunto Monumental de muy diversas épocas, a unos condicionantes muy importantes: no se trata únicamente de un yacimiento arqueológico sino que es también un conjunto patrimonial con muchas servidumbres en el tema de las infraestructuras; la electricidad, las canalizaciones de agua... etc., estaban desfasadas, algunas databan incluso de finales del siglo pasado. El nuevo proyecto contempló exclusivamente la zona externa a los palacios sin entrar prácticamente en los elementos arquitectónicos más conocidos de la Alhambra, y se establecieron una serie de medidas cautelares como, resumiendo, la realización de sondeos previos para cada tramo de zanja a abrir, la corrección en su caso y a la luz de los resultados arrojados por los sondeos de los trazados inicialmente previstos, la búsqueda de trazados alternativos para los tramos que resultaran inviables, el establecimiento de una documentación completa de memorias, planos, fotografías... etc. de lo hallado, la evaluación de los vestigios y señalamiento de su importancia, la toma de decisiones respecto al tratamiento de lo hallado, la comunicación periódica a la Comisión Técnica de la Alhambra de las incidencias arqueológicas observadas durante el desarrollo de esas obras de infraestructura, y finalmente, a lo que obliga la Ley de Patrimonio, la publicación, la edición de esos resultados. Como punto de partida de las prescripciones básicas en materia arqueológica citaremos la utilización preferente de los trazados de infraestructuras preexistentes -es decir, no crear nuevos trazados salvo que lo hallado recomendase lo contrario-. En el $90 \%$ de los casos se han utilizado los trazados anteriores, abiertos fundamentalmente en el s. XIX y a lo largo de todo el presente siglo, con frecuencia sin documentación alguna. La eliminación de las instalaciones modernas que quedaban en desuso -es decir, las canalizaciones de los años 60 , de tuberías de cemento...- se ha ido igualmente completando conforme se instalaban las nuevas, en los mismos lugares y con las mismas dimensiones. La agrupación en zanja común de las diversas instalaciones del proyecto, y la reducción a mínimos de la profundidad de zanjas y arquetas determinada por la exigencia arqueológica del trazado, completan las prescripciones establecidas.

Un instrumento fundamental desde el punto de vista arqueológico, dentro de ese apartado que llamábamos de investigación, es el Programa de Actuación Arqueológica que se estableció para la zona de los Albercones, la Zona Alta de la Alhambra, en cuya Memoria previa de 1989 figuraban tres objetivos básicos:

- Análisis de los elementos de las estructuras hidráulicas y de las redes correspondientes.

- La relación entre los elementos de la estructura hidráulica y la vegetación de la zona con el cinturón de huertas que rodean el Conjunto.

- Los mecanismos defensivos de esas estructuras hidráulicas.

No obstante, como consecuencia precisamente de esta actuación arqueológica, sin duda modélica, que todavía no se ha valorado suficientemente pero en los próximos años va a ser referente incluso a nivel internacional, se vió la necesidad de establecer un ambicioso programa más amplio dedicado exclusivamente al tema arqueológico; y aquí surgió lo que llamamos el Programa 200I de intervención arqueológica en el Conjunto monumental de la Alhambra. Es una planificación de actividades con objeto de unificar las intervenciones arqueológicas a realizar mediante un plan globalizador que eludiera las posibles contradicciones que pudieran surgir en el desa- 
rrollo de la investigación. En él se plantea el estudio fundamentalmente de la relación del monumento y su territorio, algo que estaba de espaldas hasta el momento; el estudio del sistema hidráulico que pudiera aportar claves de la colonización de la Alhambra, del mantenimiento en la propia colina y de todas las zonas subterráneas; la elaboración de un catálogo, de una cartografía, y de la recuperación de los documentos relativos a las transformaciones que se han sucedido en el monumento históricamente. El objetivo principal no era tanto descubrir nuevos hallazgos arqueológicos, sino enriquecer el reconocimiento de las distintas áreas de la Alhambra y buscar una serie de cronologías en la ocupación de su territorio. Se pretende por tanto con este nuevo instrumento ordenar el muchísimo material arqueológico, que se conoce pero que está disperso, y nos atreveríamos a decir que absolutamente desorganizado. El Programa se completa mediante una supervisión y una coordinación desde la propia estructura administrativa y de gestión del Patronato de la Alhambra que obligará una vez concluída en el año de referencia, a evaluar las actuaciones realizadas. La ejecución del Programa se ha dividido en tres trienios: del 92 al 94, en el que fundamentalmente se intervendrá en la zona de los Albercones, culminando las obras allí realizadas, y en el Palacio de los Abencerrajes, que es una especie de caja de sorpresas, y pensamos que va a ser muy importante para el conocimiento real de la Alhambra y de su evolución. También la estructura hidráulica del monumento como consecuencia precisamente de estas dos intervenciones permitirá conocer la ocupación de la colina.

Entre el año 1995 y 1997 se ha programado lo que se denominó a priori "la Alhambra subterránea", es decir, una exploración de conducciones y pasadizos, así como los problemas de conservación y constructivos de las estructuras de superficie.

Finalmente, entre 1998 y el año 2000 pretendemos que la actuación se centre en el Secano y en los ejes de comunicación de la Alhambra, concebido desde el punto de vista urbano y del propio hábitat.

La gestión patrimonial arqueológica de la Alhambra tiene estas dos vertientes: de un lado la investigación condicionada por una serie de planificaciones, y de otro, la difusión de la misma, conse- cuencia directa de la aplicación de la Ley Patrimonio Histórico Español y de Ley de Patrimonio Histórico de Andalucía, ya en vigor.

Lógicamente el eje central de la difusión para el tema de la arqueología, se centra en la revista Cuadernos de la Alhambra, con 28 años de existencia, que se distribuye en todo el mundo y que es un instrumento básico para la difusión del patrimonio de la Alhambra en general; en su apartado "Crónica de la Alhambra" se exponen puntualmente todas las actividades relacionadas con la arqueología del monumento, alcanzando casi un tercio de la revista, lo cual muestra el aspecto de la investigación en su vertiente de difusión.

Estrictamente en el tema arqueológico, aparte de dar a conocer en el futuro las investigaciones en curso, ya se han producido dos publicaciones relacionadas. La primera, editada en el año 1990, es el Coloquio sobre la Casa Hispano-musulmana, en colaboración con el Museo de Palma de Mallorca y la Casa de Velázquez, fruto del Seminario celebrado en Madrid entre arqueólogos franceses y españoles fundamentalmente. En segundo lugar se colaboró en un nuevo Coloquio en esta ocasión celebrado en la Alhambra, los Encuentros hispano-italianos de Arqueología Medieval, cuyas actas han sido editadas por el Patronato.

Otro aspecto interesante de la difusión que también emana de los propios Estatutos del Patronato y de las Leyes de Patrimonio son la convocatoria en la Alhambra de tres Encuentros anuales: el primero dedicado estrictamente a Arte, Arquitectura y Arqueología islámica, el segundo centrado en el tema del Jardín histórico y el tercero dedicado a las Bellas Artes, la Conservación y la Historia del Arte.

Un instrumento básico de difusión es el de las Visitas guiadas que organiza la propia Alhambra, abiertas al público interesado, a lugares arqueológicos, históricos, etc., que normalmente están cerrados, fruto de las cuales surgieron las visitas en colaboración con el Secretariado de Extensión Cultural de la Universidad de Granada, dirigidas fundamentalmente a estudiantes universitarios.

Los Paseos por la Alhambra, y la convocatoria de una serie de cursos desde el punto de vista del 
patrimonio histórico, y en este caso de la arqueología, como el celebrado en 1989-90 en colaboración con el Instituto Goethe sobre la introducción a la lectura de textos científicos en alemán, exclusivamente dedicado a arqueólogos e historiadores del arte, o como el que se va a celebrar próximamente de dibujo, también dedicado a arqueólogos e historiadores del arte, completan los objetivos de difusión instituidos por el Patronato de la Alhambra en relación con los propios trabajos de investigación.

En conclusión creemos que hay unos claros objetivos desde el punto de vista arqueológico y de la conservación en la Alhambra, como son la superación de ese antagonismo de la arqueología como disciplina, de lo que supone la conservación entendida como intervención arquitectónica y de la disciplina de la historia del arte; la superación de estos conflictos es el objetivo prioritario de nuestra actuación.

Otro aspecto interesante que emana de lo comentado, es la consideración de la Alhambra como objeto de una arqueología monumental, es decir, entendiendo la arqueología no sólo como arqueología del subsuelo, sino también como arqueología de paramentos o arqueología de cubiertas.

Estos planteamientos básicos se organizan consecuentemente de dos formas: por un lado, una arqueología integrada en la conservación permanente del monumento, que supone lo que llamamos la arqueología de mantenimiento, seguimiento y emergencia, y la elaboración de una serie de programas arqueológicos autónomos que tienen por parte de los servicios técnicos de la Alhambra una coordinación y una evaluación permanente.

Consecuentemente a partir de la aprobación de los nuevos Estatutos del Patronato de la Alhambra y Generalife en 1986 se ha dotado al Organismo Autónomo de una estructura de Gestión más operativa. Ésta consiste básicamente en una Dirección, como órgano fundamental de Gobierno, de la que depende directamente una Intervención Delegada de Hacienda y sustentada en dos Jefaturas de
Servicio, una de carácter administrativo -la Secretaría General- y otra de carácter técnico Conservación-. A estos servicios corresponden sendas instancias intermedias de gestión administrativa y técnica, bajo la consideración de Jefaturas de Sección, respectivamente Administración General, e Investigación y Promoción Cultural. Existen otras dos instancias de carácter fundamentalmente técnico como son los Departamentos de Restauración y de Obras y Jardines. Todo el organigrama de Gestión se ve completado por un instrumento básico para su documentación cual es la Biblioteca y Archivo.

Dentro del modelo de gestión e investigación de la Alhambra y en referencia al marco general de estas ponencias, vemos cómo claramente el problema se manifiesta en una doble vertiente: la Investigación y la Difusión. Recientemente el Patronato de la Alhambra ha finalizado un proyecto representativo de lo que supone la integración de ambos planos en una adecuada gestión patrimonial: la Sala de Presentación del Monumento. La consecuencia de este objetivo, pionero a nivel nacional, es un modelo de integración pluridisciplinar, en la que tras una idea conceptual, plasmada en una dirección proyectual han venido participando todas y cada una de las instancias técnicas y administrativas del Patronato de la Alhambra. No es el lugar ni el momento de exponer el contenido de la Sala, por otro lado ya suficientemente conocida por todos, pero sí la he considerado significativa de lo que podría ser una perfecta integración para la consecución de lo que podríamos denominar un "modelo de gestión Alhambra". Con ello no pretendemos situar el esquema operativo de la Alhambra aplicable a otros conjuntos de similares características. Simplemente hemos tratado de evocar cómo unos objetivos demandan unos medios de los cuales, a su vez, emanan unos resultados. Bien es cierto que el Patronato de la Alhambra cuenta para ello con una dilatada historia, cuyas raíces -también operativas y de gestión- se hunden en la segunda mitad del pasado siglo. Tal vez es precisamente esto lo que da riqueza, significado y validez a una gestión, en nuestro caso, aplicada al legado del Patrimonio Histórico. 